\title{
Dental Students' Perceived Level of Competence in Orofacial Pain
}

\author{
Aurelio A. Alonso, D.D.S., M.S., Ph.D.; Masahiro Heima, D.D.S., Ph.D.; \\ Lisa A. Lang, D.M.D., M.B.A.; Sorin T. Teich, D.M.D., M.B.A.
}

Abstract: Orofacial pain (OFP) is a group of symptoms affecting a significant portion of the population; inadequate diagnosis and management of these symptoms present a potential detrimental effect on the public's health. It has been suggested that dental schools must prepare their graduates to deal with these problems rather than relying on their participation in continuing education courses after graduation. The aim of this study was to determine how third- and fourth-year students at one dental school perceived their level of competence related to OFP. Out of 140 students who were sent the survey, seventy-four (53 percent response rate) completed it in its entirety. The cross-sectional survey included questions regarding the students' familiarity with the categories of OFP. Questions asked how they perceived their knowledge in each of these areas, how comfortable they felt providing diagnosis and treatment, and if more knowledge was needed. The results showed that the fourth-year students were more comfortable than the third-year students in diagnosing and managing intraoral pain. Multiple comparisons also showed statistically significant differences between OFP categories for questions related to perceived knowledge, comfort in diagnosing and treating, and perceived need for more information. Overall, the students' perceived knowledge of and confidence in treating OFP varied with respect to certain categories, being lowest for psychogenic pain.

Dr. Alonso is Assistant Professor, Department of Comprehensive Care, School of Dental Medicine, Case Western Reserve University; Dr. Heima is Assistant Professor, Department of Pediatric Dentistry, School of Dental Medicine, Case Western Reserve University; Dr. Lang is Associate Professor, Assistant Dean of Clinical Education, and Chair, Department of Comprehensive Care, School of Dental Medicine, Case Western Reserve University; and Dr. Teich is Associate Professor and Associate Dean of Clinical Operations, Department of Comprehensive Care, School of Dental Medicine, Case Western Reserve University. Direct correspondence and requests for reprints to Dr. Aurelio A. Alonso, Department of Comprehensive Care, School of Dental Medicine, Case Western Reserve University, 2124 Cornell Road, Cleveland, OH 44106; 216-368-2486; aurelio.alonso@case.edu.

Keywords: dental education, dental students, orofacial pain, temporomandibular disorder

Submitted for publication 10/23/13; accepted 2/20/14

$\mathrm{O}$ rofacial pain (OFP) is defined as pain associated with the hard and soft tissues of the head, face, and neck. ${ }^{1}$ OFP has a median prevalence of 13 percent (range 1-48 percent), ${ }^{2}$ so inadequate recognition, diagnosis, and management of this group of symptoms will have a detrimental effect on the public's health. ${ }^{3}$ Two decades ago, in the United States alone, 13 million people experienced chronic OFP that required treatment ${ }^{4}$; more recently, it was reported that 15 percent of U.S. adults experienced migraines or headaches. ${ }^{5}$ Persistent and chronic pain is more prevalent in the head and neck region than in any other part of the body., ${ }^{2,4,6,7}$ The challenge of diagnosing and managing these problems is compounded by the fact that graduates from dental schools have reported feeling less competent in their ability to recognize myofacial pain and temporomandibular joint disorders, compared to their reports in regard to "bread and butter" items of dentistry such as basic restorative and periodontal procedures. ${ }^{8,9}$ This educational challenge should be met by predoctoral curriculum changes rather than a reliance on continuing education courses to set the knowledge standard for diagnosis and management of these disorders. ${ }^{10}$ Furthermore, it has become evident that qualitative and quantitative standards are needed to ensure that all predoctoral dental students learn diagnosis and management of non-dental OFP problems. ${ }^{11}$ In this context, interprofessional education was recently mentioned as a platform to promote multidisciplinary training in relation to OFP. ${ }^{12}$

For many years, dental educators interested in developing OFP syllabi for predoctoral programs faced significant academic challenges. ${ }^{13}$ Several conferences were held to develop and implement the teaching of temporomandibular disorders (TMD) and OFP in predoctoral and graduate dental curricula. ${ }^{13-17}$ In 2007, Klasser and Greene reported on a survey of U.S. and Canadian dental schools regarding their predoctoral teaching of TMD and found significant improvement in the curriculum content. ${ }^{11}$ However, they noted that some institutions were still not providing this instruction appropriately, thus exposing patients to a variety of treatment modalities that are not always evidence-based. Similar conclusions were drawn in a study that determined levels of knowledge about pain were consistently low among dental students. ${ }^{18}$ 
National support for OFP education has been building. The International Association for the Study of Pain (IASP) has recognized the OFP discipline as a component of professional education and developed a core curriculum on this subject for all health care professionals. ${ }^{19}$ In 2010, the American Association for Dental Research (AADR) revised its TMD Policy Statement to recommend that OFP differential diagnosis and treatment plans should be based on evidence from clinical trials as well as on experimental and epidemiologic studies. ${ }^{20}$ Recently, the Commission on Dental Accreditation (CODA) approved accreditation standards for advanced general education programs in OFP. ${ }^{21}$ Although this document supports the importance of the topic in graduate programs, it lends no support to the predoctoral curriculum.

The American Dental Education Association (ADEA) Competencies for the New General Dentist state that graduates must be competent to prevent, diagnose, and manage TMDs (section 6.9). ${ }^{22}$ Based on this exhortation, dental schools around the country should be motivated to use their predoctoral curricula to better prepare students to be able to identify and manage these OFP disorders in their future practices. ${ }^{12}$ These competencies, however, were not specifically addressed in the new CODA standards; searching the document for the word "pain" generated only one result in Standard 2-23.e., with no specific relation to TMD or OFP. ${ }^{23}$

At Case Western Reserve University School of Dental Medicine, the TMD and OFP course is taught during the fall semester of the third year. This twocredit-hour course follows relevant material taught in the first and second years of the curriculum (Table 1). The course includes seven hours of TMD-related lectures, as well as two hours related to primary headache disorders, two hours related to neuropathic pain, one hour recapitulating information provided in previous courses related to intraoral pain, and one hour related to psychogenic pain. The course also has a six-hour laboratory/clinical component during which students fabricate and fit a nightguard for one of their peers.

There are no previous reports that describe how third- and fourth-year dental students perceive their competence related to OFP. The aim of this study was to determine how students perceived the level of OFP competence they have achieved during their education at Case Western Reserve University School of Dental Medicine. We hypothesized that fourth-year students would report significantly more knowledge

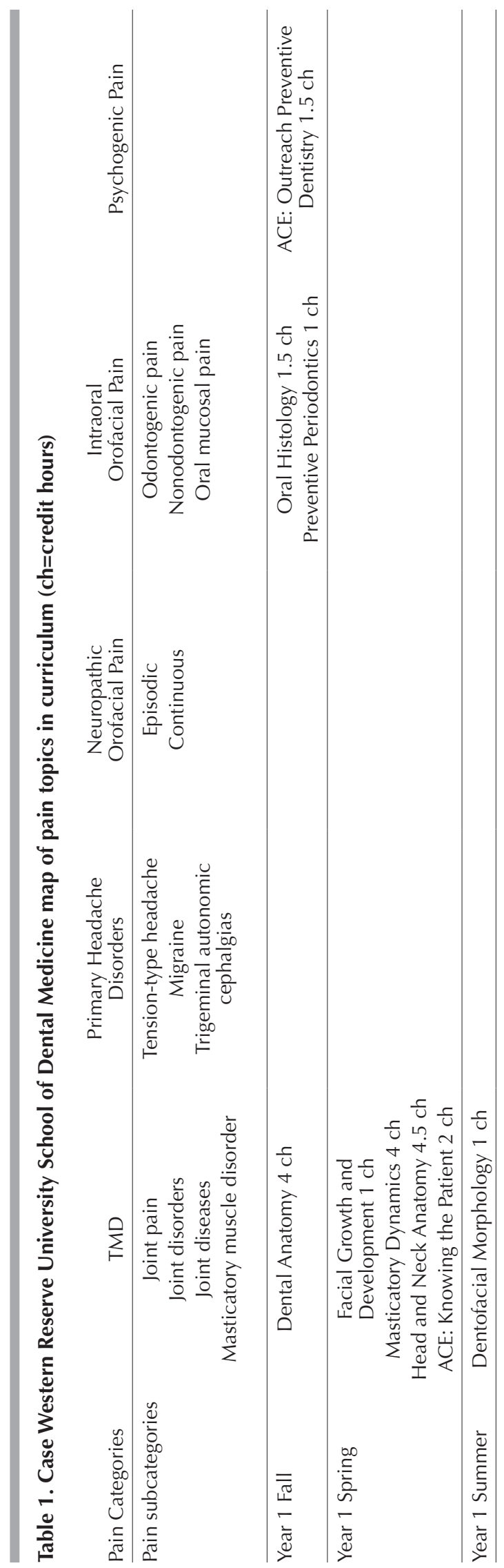




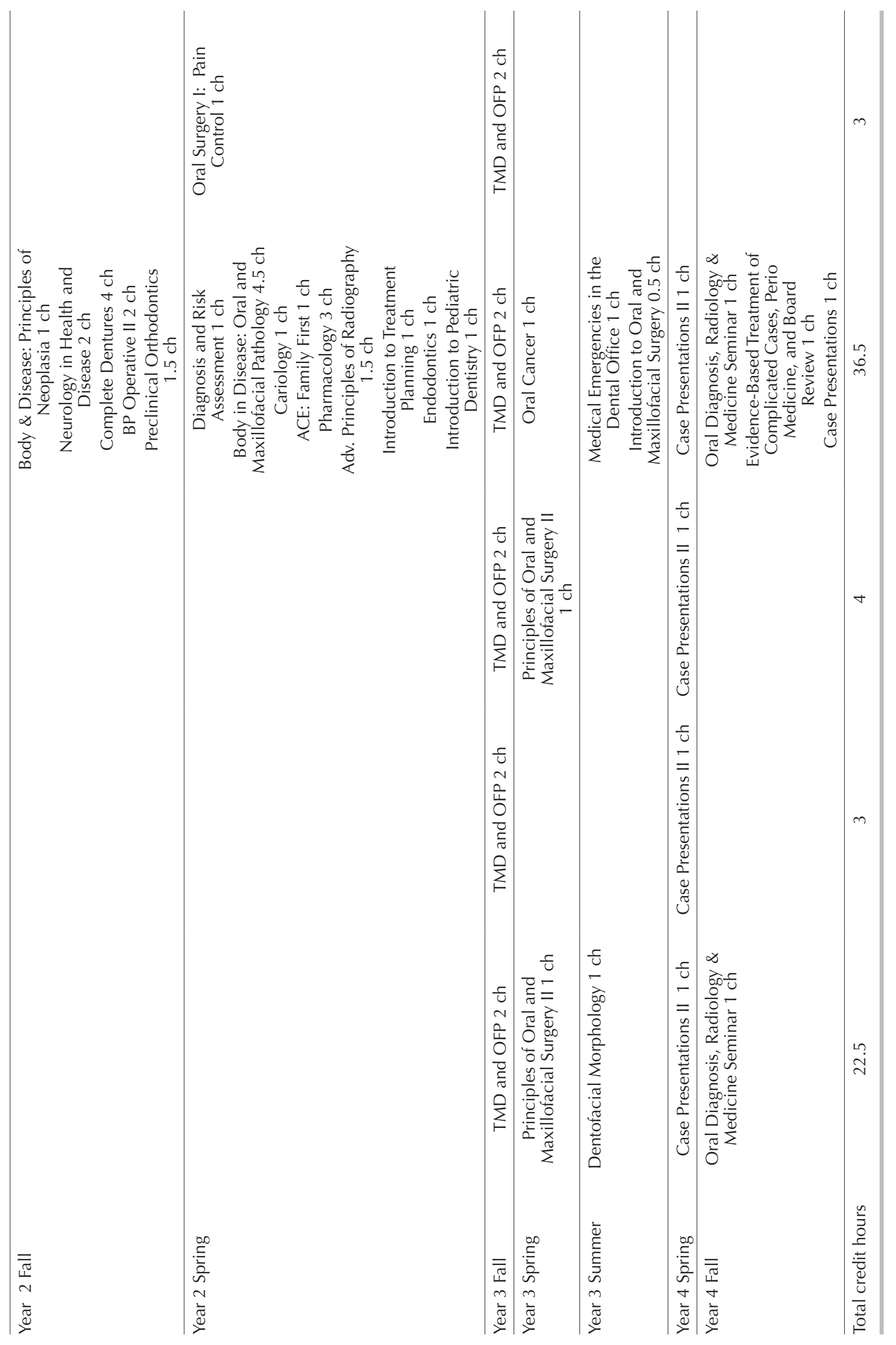


than third-year students in each OFP subset (TMD, primary headache disorders, neuropathic pain disorders, intraoral pain disorders, and psychogenic pain ${ }^{1}$ ) and that there would be no difference in the students' reported knowledge among the five OFP categories.

\section{Methodology}

The research protocol for this study was reviewed and exempted by Case Western Reserve University's Institutional Review office. A crosssectional survey was administered to the third- and fourth-year dental students at Case Western Reserve University. A total of 140 students were sent the survey distributed via email through the university's email list. Data were collected using SurveyMonkey. Three emails were sent to the students as reminders to complete the survey. The first email contained information about the survey and the link that allowed them access to it. A second email was sent two weeks later as a reminder, followed by a third and final email reminder two weeks later.

The survey included questions regarding the students' familiarity with the categories of OFP: TMD, primary headache disorders, neuropathic pain disorders, intraoral pain disorders, and psychogenic pain disorders. For each OFP category, students were asked how they perceive their knowledge in it, how comfortable they feel providing diagnosis and treatment, and if they think they need more knowledge. The survey was structured according to the OFP categories presented in the third-year OFP management course (Table 1). At the end of the survey, students answered the following general question about OFP as a comprehensive topic: "What level of OFP complexity would you like to treat after graduation?"

IBM SPSS version 20 (IBM Corporation, Armonk, NY, USA) was used for statistical analysis. Response options for questions two to five were on five-point rating scales. ${ }^{24} \mathrm{~A}$ t-test was used to determine statistical significance at $p<0.05$. The distribution of being familiar with the terms in each OFP category was assessed with a chi-square test. The General Linear Model (GLM) for Repeated Measures was used to analyze responses to the second through fifth questions. The following analytic sequence was applied. First, data were evaluated with Mauchly's sphericity test to identify violations or sphericity $(p<0.05)$. Second, if the sphericity assumption was violated, the degrees of freedom were corrected using the lower bound correction to avoid increase in Type I errors. Third, the GLM omnibus analysis was performed to determine if the data contained significant differences between OFP categories or between third- and fourth-year students. Fourth, if the results obtained with the GLM analysis denoted that statistically significant differences existed, multiple comparisons using the Fisher Least Significant Differences (LSD) test were applied to determine specific differences between OFP categories. For each question, if no statistically significant difference was identified between third- and fourth-year students, the comparisons used pooled answers of all students into a single set of data for each OFP category. Statistical significance was determined at $\mathrm{p}<0.05$.

\section{Results}

Out of 140 students who were sent the survey, a total of seventy-four (53 percent response rate) completed it in its entirety. These participants consisted of thirty-six third-year students and thirty-eight fourth-year students.

On question 1 (familiarity with OFP terms), all seventy-four students were familiar with the term TMD. The third- and fourth-year students were familiar with all other OFP terms to some extent (Table 2), but no statistical significance was found between the two classes in each category (chi-square tests were used to assess the distribution of familiarity with the terms in each OFP category).

Regarding question 2 (perceived degree of knowledge), the following results were generated under condition of the sphericity assumed: $\chi 2=6.41$, $\mathrm{df}=9, \mathrm{p}=0.698$. The results denote that sphericity was not violated, and therefore the lower bound correction was not necessary. The main effect of differences of OFP categories indicated there were significant differences among the OFP categories ( $F=34.937, p<0.001)$; however, the main effect of the difference between the two groups did not indicate an overall significant influence on perceived degree of knowledge $(\mathrm{F}=1.020, \mathrm{p}=0.318)$. The third-year students said they felt significantly more knowledgeable than the fourth-year students only regarding primary headaches $(\mathrm{t}=4.10, \mathrm{df}=65, \mathrm{p}<0.001)$. No significant differences between the two classes were found for other categories of OFP (Table 3). Multiple comparisons (data not shown) showed that students perceived having most knowledge in intraoral pain, followed by TMD and neuropathic pain; the differences between these categories were 
significant. Primary headaches and psychogenic pain were perceived by the students as categories in which they had significantly less knowledge compared to the other three categories; the difference between primary headaches and psychogenic pain was not statistically significant $(\mathrm{p}=0.070)$.

For question 3 (perceived comfort to diagnose OFP), the following results were generated under condition of the sphericity assumed: $\chi 2=9.44, \mathrm{df}=9$, $\mathrm{p}=0.398$. The results denoted that sphericity was not violated, so the lower bound correction was not necessary. The main effect of differences of OFP categories indicated there were significant differences among the OFP categories $(F=56.85, \mathrm{p}<0.001)$; however, the main effect of the difference between third- and fourth-year students did not indicate overall significant influence on perceived comfort to diagnose $(\mathrm{F}=0.069, \mathrm{p}=0.794)$. The fourth-year students felt significantly more comfortable in the diagnosis of intraoral pain $(\mathrm{t}=2.41, \mathrm{df}=68, \mathrm{p}=0.019)$ than did the third-year students. There was no significant difference between the two classes' level of comfort in the diagnosis of other OFP categories (Table 4). Multiple comparisons (data not shown) showed students' feeling most comfortable diagnosing intraoral pain, followed by TMD $(p<0.001)$. Neuropathic pain and primary headaches were not statistically different, but both were reported as significantly lower when compared to TMD ( $\mathrm{p}=0.003$ and $\mathrm{p}<0.001$, respectively). Finally, the students reported feeling significantly less comfortable diagnosing psychogenic pain compared to neuropathic pain $(\mathrm{p}<0.001)$, but no difference was reported in comparison to primary headaches $(\mathrm{p}=0.069)$.

Regarding question 5 (perceived comfort to manage OFP), the following results were generated under condition of the sphericity assumed: $\chi 2=$ $18.315, \mathrm{df}=9, \mathrm{p}=0.032$. The results denoted that the

Table 2. Students' familiarity with each of five OFP areas, by number and percentage of respondents in each class who responded yes to each item

Are you familiar with the term ...

\begin{tabular}{lccccc}
\hline Class & TMD & Primary Headaches & Neuropathic Pain & Intraoral Pain & Psychogenic Pain \\
\hline Third-year students & $36(100 \%)$ & $34(94.4 \%)$ & $33(91.7 \%)$ & $34(94.4 \%)$ & $25(69.4 \%)$ \\
Fourth-year students & $38(100 \%)$ & $33(86.8 \%)$ & $31(81.6 \%)$ & $36(94.7 \%)$ & $21(55.3 \%)$ \\
\hline
\end{tabular}

Table 3. Students' perceived degree of knowledge in the five OFP areas, by average (standard deviation) for each class regarding each item

What is your degree of knowledge related to ...

\begin{tabular}{lccccc}
\hline Class & $\begin{array}{c}\text { TMD } \\
\text { Avg (SD) }\end{array}$ & $\begin{array}{c}\text { Primary Headaches } \\
\text { Avg (SD)* }\end{array}$ & $\begin{array}{c}\text { Neuropathic Pain } \\
\text { Avg (SD) }\end{array}$ & $\begin{array}{c}\text { Intraoral Pain } \\
\text { Avg (SD) }\end{array}$ & $\begin{array}{c}\text { Psychogenic Pain } \\
\text { Avg (SD) }\end{array}$ \\
\hline Third-year students & $3.47(0.70)$ & $3.44(0.86)$ & $3.36(0.78)$ & $4.09(0.57)$ & $2.72(0.79)$ \\
Fourth-year students & $3.45(0.72)$ & $2.58(0.87)$ & $3.13(0.96)$ & $4.17(0.85)$ & $2.62(1.02)$
\end{tabular}

*Statistically significant difference between classes

Note: Response options ranged from 1 to 5 with $1=$ not knowledgeable and $5=$ knowledgeable.

Table 4. Students' level of comfort in diagnosing the five OFP areas, by average (standard deviation) for each class regarding each item

How comfortable do you feel diagnosing patients with . . .

\begin{tabular}{lccccc}
\hline Class & $\begin{array}{c}\text { TMD } \\
\text { Avg (SD) }\end{array}$ & $\begin{array}{c}\text { Primary Headaches } \\
\text { Avg (SD) }\end{array}$ & $\begin{array}{c}\text { Neuropathic Pain } \\
\text { Avg (SD) }\end{array}$ & $\begin{array}{c}\text { Intraoral Pain } \\
\text { Avg (SD)* }\end{array}$ & $\begin{array}{c}\text { Psychogenic Pain } \\
\text { Avg (SD) }\end{array}$ \\
\hline Third-year students & $3.03(0.74)$ & $2.68(0.77)$ & $2.48(0.87)$ & $3.76(0.61)$ & $2.32(0.75)$ \\
Fourth-year students & $2.89(0.73)$ & $2.30(0.92)$ & $2.58(0.92)$ & $4.17(0.77)$ & $2.19(0.68)$
\end{tabular}

*Statistically significant difference between classes

Note: Response options ranged from 1 to 5 with $1=$ very uncomfortable and $5=$ very comfortable. 
sphericity assumption was violated; therefore, the lower bound correction was necessary and subsequently applied. The main effect of differences of OFP categories indicated there were significant differences among the OFP categories $(\mathrm{F}=75.92, \mathrm{p}<0.001)$; however, the main effect of the difference between the two classes did not indicate overall significant influence on the overall perceived comfort in managing OFP $(\mathrm{F}=0.121, \mathrm{p}=0.730)$ (Table 5). The fourth-year students felt significantly more comfortable than the third-year students in managing intraoral pain $(\mathrm{t}=2.88$, $\mathrm{df}=68, \mathrm{p}=0.005)$. There was no significant difference between the two classes in their level of comfort in managing the other OFP categories. Multiple comparisons (data not shown) showed students' feeling most comfortable managing intraoral pain, followed by TMD $(p<0.001)$. Neuropathic pain and primary headaches were not statistically different, but both were reported as significantly lower when compared to TMD ( $p<0.001$ and $p=0.042$, respectively). While students reported feeling significantly less comfortable treating psychogenic pain compared to intraoral pain and TMD $(p<0.001)$, no difference was found in comparing it to neuropathic pain $(\mathrm{p}=0.476)$ and primary headaches $(\mathrm{p}=0.052)$.

On question 5 (perceived need for more knowledge), the following results were generated under condition of the sphericity assumed: $\chi 2=15.95, \mathrm{df}=9$, $p=0.0682$. The results denoted that sphericity was not violated, so the lower bound correction was not necessary. The main effect of differences of OFP categories indicated there were significant differences among the OFP categories $(F=3.165, p<0.015)$; however, the main effect of the difference between the third- and fourth-year students did not indicate overall significant influence on perceived need for more knowledge $(\mathrm{F}=3.131, \mathrm{p}=0.084)$. All the students (100 percent) reported thinking they needed more knowledge in relation to the five areas of OFP. The fourth-year students reported statistically significant more need for knowledge regarding primary headaches compared with the third-year students $(\mathrm{t}=4.24$, $\mathrm{df}=55.67, \mathrm{p} \leq 0.001)$. Also, the third-year students felt a significant need for more knowledge in relation to intraoral pain than did the fourth-year students $(\mathrm{t}=2.07, \mathrm{df}=64.70, \mathrm{p}=0.042)$ (Table 6). Multiple comparisons (data not shown) showed students' perceiving the need for more knowledge in most categories; the single area that was reported to be significantly different was intraoral pain, which had a statistically significant lower score compared to TMD, primary headaches, and psychogenic pain $(\mathrm{p}=0.003, \mathrm{p}=0.009$, $\mathrm{p}=0.033$, respectively).

Regarding the final question (level of OFP patient complexity students would like to treat after graduation), the majority of both classes ( 80 percent

Table 5. Students' level of comfort in managing the five OFP areas, by average (standard deviation) for each class regarding each item

How comfortable do you feel managing patients with . . .

\begin{tabular}{lccccc}
\hline Class & $\begin{array}{c}\text { TMD } \\
\text { Avg (SD) }\end{array}$ & $\begin{array}{c}\text { Primary Headaches } \\
\text { Avg (SD) }\end{array}$ & $\begin{array}{c}\text { Neuropathic Pain } \\
\text { Avg (SD) }\end{array}$ & $\begin{array}{c}\text { Intraoral Pain } \\
\text { Avg (SD)* }\end{array}$ & $\begin{array}{c}\text { Psychogenic Pain } \\
\text { Avg (SD) }\end{array}$ \\
\hline Third-year students & $2.50(0.88)$ & $2.47(0.83)$ & $2.21(0.82)$ & $3.65(0.73)$ & $2.16(0.75)$ \\
Fourth-year students & $2.42(0.89)$ & $2.09(0.91)$ & $2.00(1.00)$ & $4.17(0.77)$ & $2.05(0.74)$
\end{tabular}

*Statistically significant difference between classes

Note: Response options ranged from 1 to 5 with $1=$ very uncomfortable and $5=$ very comfortable.

Table 6. Students' perceived need for more knowledge in the five OFP areas, by average (standard deviation) for each class regarding each item

Do you think you need more knowledge related to . . .

\begin{tabular}{lccccc}
\hline Class & $\begin{array}{c}\text { TMD } \\
\text { Avg (SD) }\end{array}$ & $\begin{array}{c}\text { Primary Headaches } \\
\text { Avg (SD) }\end{array}$ & $\begin{array}{c}\text { Neuropathic Pain } \\
\text { Avg (SD) }\end{array}$ & $\begin{array}{c}\text { Intraoral Pain } \\
\text { Avg (SD)* }\end{array}$ & $\begin{array}{c}\text { Psychogenic Pain } \\
\text { Avg (SD) }\end{array}$ \\
\hline Third-year students & $3.89(0.62)$ & $3.47(0.90)$ & $3.73(0.94)$ & $3.68(0.68)$ & $3.60(1.15)$ \\
Fourth-year students & $4.03(0.64)$ & $4.24(0.56)$ & $3.94(0.77)$ & $3.28(0.91)$ & $4.05(0.67)$
\end{tabular}

* Statistically significant difference between classes

Note: Response options ranged from 1 to 5 with $1=$ strongly disagree and $5=$ strongly agree. 
of the third-year students and 72.2 percent of the fourth-year students) reported they would like to treat simple cases of OFP. A minority (6.7 percent of the third-year students and 9.1 percent of the fourth-year students) said they do not want to treat any type of OFP. At the other extreme, 3.3 percent of the third-year students and 6.1 percent of the fourthyear students said they would like to treat complex cases (Table 7). There were no significant differences between the two classes regarding their preferences (Pearson chi-square $=0.535, \mathrm{df}=3, \mathrm{p}=0.911$ ).

\section{Discussion}

For decades, educators in the pain field have been trying to develop and standardize a TMD and OFP curriculum for predoctoral and postdoctoral dental students. ${ }^{11,14,16,17,25}$ Our study is unique because it is the first time students' insights regarding their current perceived knowledge and level of comfort in diagnosis and management are reported, as well as their future plans to be involved in the OFP field. The dental profession is no longer limited to the oral cavity; dentists and future dentists are playing an important role in the diagnosis and management of OFP and TMD and related areas. ${ }^{13}$ For this reason, future dentists and general practitioners should be able to develop differential diagnoses, provide appropriate treatment for simple cases, and identify the most complex cases for referral to practitioners with specific OFP training. ${ }^{26}$

Our results showed that this dental school's third- and fourth-year students were familiar with all five categories of OFP; the single category in which both classes reported being less familiar was psychogenic pain, probably because this topic is less integral to our curriculum (see Table 1). Although the students reported being knowledgeable regarding TMD and intraoral pain, they also felt the need for more knowledge to become more comfortable in managing these disorders. For example, the fact that the third-year students reported they feel less comfortable diagnosing and managing patients with intraoral pain and also reported needing more knowledge related to this OFP category can be explained by their limited clinical exposure.

The third-year students reported feeling more knowledgeable than did the fourth-year students in the primary headaches field. The reason could be that the OFP course is offered during the third year so the didactic material related to this category was fresh in their minds. Another possibility is that fourth-year students, who have more clinical experience, have been exposed to some cases of primary headaches that made them realize this entity is complex and that diagnosis and treatment are more difficult than was presented in the didactic third-year course. This may also explain why fourth-year students perceived that they needed more knowledge in this category when compared to the third-year students. The multiple comparisons analysis revealed the order of perceived knowledge for the OFP categories: intraoral pain was followed by TMD and neuropathic pain, while the least knowledge was reported in relation to primary headaches and psychogenic pain. These results should also be considered in tandem with responses to the fifth question, showing that students need more information in all OFP categories and affirmed their willingness to learn more about symptoms not related to the intraoral pain category.

It is natural for fourth-year students to feel more comfortable than their third-year colleagues diagnosing and managing patients with intraoral pain because these symptoms are encountered in the clinic on a daily basis. However, patients with psychogenic pain symptoms are not often seen in the clinic, so students do not get the necessary clinical training beyond the limited didactic exposure. In fact, most informed pain clinicians agree that psychogenic pain is a rare occurrence despite chronic pains having a certain component of psychogenic etiology. ${ }^{27}$

Table 7. Students' preference for level of complexity of OFP cases they would like to treat after graduation, by number and percentage of respondents in each class

What level of OFP complexity would you like to treat after graduation?

\begin{tabular}{lcccc}
\hline Class & $\begin{array}{c}\text { I do not want to treat } \\
\text { any type of OFP }\end{array}$ & $\begin{array}{c}\text { Both complex and } \\
\text { simple cases }\end{array}$ & $\begin{array}{c}\text { Simple } \\
\text { cases }\end{array}$ & $\begin{array}{c}\text { Complex } \\
\text { cases }\end{array}$ \\
\hline Third-year students & $2(6.7 \%)$ & $3(10.0 \%)$ & $24(80.0 \%)$ & $1(3.3 \%)$ \\
Fourth-year students & $3(9.1 \%)$ & $4(12.1 \%)$ & $24(72.7 \%)$ & $2(6.1 \%)$ \\
\hline \hline
\end{tabular}


Answers to the third and fourth questions analyzed with multiple comparisons showed a similar reported pattern regarding students' comfort with diagnosing and managing OFP symptoms. Intraoral pain was perceived as the area where the students felt most comfortable, followed by TMD, followed by a group of the other OFP categories (neuropathic pain, primary headaches, and psychogenic pain). These results can also be explained by the amount of exposure related to different OFP categories that students receive both in the didactic curriculum and through clinical experience.

The aim of predoctoral dental curricula is to provide education that will allow the graduate "to function as an entry-level, beginning general dentist." ${ }^{23}$ Our results showed that the students expressed the need for more information related to OFP, while recognizing that in practice they will see mainly "simple" (entry-level) cases. These results require a cautious interpretation because the students' willingness to limit their future practice mainly to simple OFP cases may be related to concerns that their didactic and clinical training in this area was not sufficient. Further research may elucidate if more robust OFP didactic and clinical training impacts students' preferences to treat more complex cases after graduation.

When teaching OFP, it is a sine qua non that dental students learn how to evaluate, detect, make differential diagnosis, and provide appropriate management. If they are not comfortable managing these disorders, they should be able to recognize the complexity of the case and make the appropriate referral (CODA Standard 2-23c) ${ }^{23}$ Complex patients are best managed when referred to a multidisciplinary pain service providing treatment by physicians, dentists, physical therapists, and behavior therapists. ${ }^{10,12}$ Therefore, an understanding of standards for referral to improve patient care is required.

The multidisciplinary approach is related also to interprofessional education that is no longer merely a school-related preference. The preamble of the CODA standards makes clear that "Health care professionals educated to deliver patient-centered care as members of an interdisciplinary team present a challenge for educational programs. ... Dental education programs are to seek and take advantage of opportunities to educate dental school graduates who will assume new roles in safeguarding, promoting, and caring for the health care needs of the public." ${ }^{\prime 23}$ Additional emphasis on this topic can be found in CODA Standards 1-9, 2-10, and 2-19. Although syllabi related to OFP should pay more attention to the "hands-on" clinical component, ${ }^{10}$ we also should recognize that dental education has a great opportunity to use the OFP topic as a bridge to a medical management way of thinking that promotes interdisciplinary education. ${ }^{12}$ However, this opportunity can be missed both because the predoctoral CODA standards have no emphasis on OFP and because many programs aimed at training physicians do not have dedicated OFP syllabi. ${ }^{28,29}$

We recognize that our study has limitations. First, the response rate to our survey limited the sample size. Second, every school has certain characteristics and teaching philosophies that are reflected in their syllabi, so our sample may not be representative of all students in the United States. We believe, however, that the results presented in this study may serve as a starting point to raise awareness for further development of teaching methods regarding OFP and guidelines for syllabi intended to better train graduates, emphasize the need for referral and interprofessional education, and improve patient care. ${ }^{12,30}$

\section{Conclusion}

This study found that the Case Western Reserve University third- and fourth-year dental students' perceived familiarity with OFP varied in relation to specific categories, being lowest for psychogenic pain. The first hypothesis was rejected in most categories, with the exception of intraoral pain; fourthyear students reported being more comfortable than third-year students in diagnosing and managing this category. The second hypothesis was also rejected based on the multiple comparisons analysis that showed statistically significant differences between OFP categories for questions related to perceived knowledge, comfort to diagnose and treat, and perceived need for more information. Overall, the question remains as to how the entry-level dentist will determine which cases are "simple" enough to be treated in the practice and which level of case complexity has to be referred. We think that there is an acute need to establish standards for appropriate referral that are understood by all dental school graduates.

\section{REFERENCES}

1. de Leeuw R, Klasser GD. Orofacial pain: guidelines for assessment, diagnosis, and management. 5th ed. Hanover Park, IL: Quintessence, 2013. 
2. Macfarlane TV, Glenny AM, Worthington HV. Systematic review of population-based epidemiological studies of orofacial pain. J Dent 2001;29(7):451-67.

3. Madland G, Newton-John T, Feinmann C. Chronic idiopathic orofacial pain: what is the evidence base? Br Dent J 2001;191(1):22-4.

4. Lipton JA, Ship JA, Larach-Robinson D. Estimated prevalence and distribution of reported orofacial pain in the United States. J Am Dent Assoc 1993;124(10):115-21.

5. Plesh O, Adams SH, Gansky SA. Self-reported comorbid pains in severe headaches or migraines in a U.S. national sample. Headache 2012;52(6):946-56.

6. Koratkar HPJ. Atypical odontalgia: a review. Northwest Dent 2008;87(1):37-8,62.

7. Hardt J, Jacobsen C, Goldberg J, et al. Prevalence of chronic pain in a representative sample in the United States. Pain Med 2008;9(7):803-12.

8. Greenwood L, Lewis D, Burgess R. How competent do our graduates feel? J Dent Educ 1998;62(4):307-13.

9. Holmes D, Diaz-Arnold A, Williams V. Alumni selfperception of competence at time of dental school graduation. J Dent Educ 1997;61(6):465-72.

10. Gonzalez YM, Mohl ND. Care of patients with temporomandibular disorders: an educational challenge. J Orofac Pain 2002;16(3):200-6.

11. Klasser GD, Greene CS. Predoctoral teaching of temporomandibular disorders: a survey of U.S. and Canadian dental schools. J Am Dent Assoc 2007;138(2):231-7.

12. Klasser GD, Gremillion HA. Past, present, and future of predoctoral dental education in orofacial pain and TMDs: a call for interprofessional education. J Dent Educ 2013;77(4):395-400.

13. Attanasio R. The study of temporomandibular disorders and orofacial pain from the perspective of the predoctoral dental curriculum. J Orofac Pain 2002;16(3):176-80.

14. Attanasio R, Mohl ND. Suggested curriculum guidelines for the development of continuing education programs in TMD and orofacial pain. J Craniomandibular Disorders 1992;6(2):137-40.

15. Fricton JR. Development of orofacial pain programs in dental schools. J Orofac Pain 2002;16(3):191-7.

16. Greene CS, Stockstill JW, Clark GT. Predoctoral education for TMD and orofacial pain: a philosophical overview. J Craniomandibular Disorders 1992;6(2):111-2.
17. Mohl ND, Attanasio R. The third educational conference to develop the curriculum in temporomandibular disorders and orofacial pain: introduction. J Orofac Pain 2002;16(3):173-5.

18. Borromeo GL, Trinca J. Understanding of basic concepts of orofacial pain among dental students and a cohort of general dentists. Pain Med 2012;13(5):631-9.

19. Charlton JE. Core curriculum for professional education in pain. Seattle: IASP Press, 2005.

20. American Association for Dental Research. AADR TMD policy statement revision. Alexandria, VA: American Association for Dental Research, 2010.

21. Commission on Dental Accreditation. Accreditation standards for advanced education general dentistry programs in orofacial pain. Chicago: American Dental Association, 2009.

22. American Dental Education Association. ADEA competencies for the new general dentist. J Dent Educ 2012;76(7):891-4

23. Commission on Dental Accreditation. Accreditation standards for dental education programs. At: www.ada org/sections/educationAndCareers/pdfs/predoc_2013.pdf. Accessed: October 23, 2013.

24. Likert R. A technique for the measurement of attitudes. Archiv Psychol 1932;22(140):1-55.

25. Stockstill JW. Curriculum outline for adjunctive predoctoral education in TMD and orofacial pain. J Craniomandibular Disorders 1992;6(2):117-22.

26. Steenks MH. The gap between dental education and clinical treatment in temporomandibular disorders and orofacial pain. J Oral Rehabil 2007;34(7):475-7.

27. Okeson JP. Bell's orofacial pains: the clinical management of orofacial pain. St. Louis, MO: Quintessence, 2005.

28. Lukachko A. Pain education lacking in medical school curricula. Prim Care Q 2009;5(9).

29. Ivanoff CS, Hottel TL. A four-tier problem-solving scaffold to teach pain management in dental school. J Dent Educ 2013;77(6):723-31.

30. Nilner M. Curriculum guidelines for orofacial pain and temporomandibular disorders, European Academy of Craniomandibular Disorders. Eur J Dent Educ 2001;5(3): 136-8. 